\title{
The Methods for Direct Detection of WIMP with Mass $\leq 0.5 \mathrm{GeV} / \mathrm{c}^{2}$
}

\author{
B.M.Ovchinnikov", I.I.Tkachev, V.V.Parusov \\ Institute for Nuclear Research, Russian Academy of Sciences, Russia
}

Copyright $(C 2015$ by authors, all rights reserved. Authors agree that this article remain permanently open access under the terms of the Creative Commons Attribution License 4.0 International License

\begin{abstract}
The chamber for direct detection of WIMP with mass $\leq 0.5 \mathrm{Gev} / \mathrm{c}^{2}$ was developed. The chamber is filled with gas mixture $\mathrm{Ne}+10 \% \mathrm{H}_{2}(0-1$ bar $)+0,15 \mathrm{ppm} \mathrm{Ge}\left(\mathrm{CH}_{3}\right)_{4}$. For events detections used GEM+pin-anode, which provides the energy threshold about $\mathrm{eV}$. The electron background is suppressed owing to photosensitive addition $\mathrm{Ge}\left(\mathrm{CH}_{3}\right)_{4}$. It is proposed also for direct detection of WIMP the liquid argon chamber with $\mathrm{H}_{2}$ dissolved in liquid argon at a concentration $100 \mathrm{ppm}+0,015 \mathrm{ppm} \mathrm{Ge}\left(\mathrm{CH}_{3}\right)_{4}$.
\end{abstract}

Keywords Search the Low Mass WIMP, Metallic GEM+pin-anode, The Energy Threshold about eV

\section{Introduction}

The detectors with pure $\mathrm{NaI}, \mathrm{Xe}$, or Ar allow to search the WIMP with large mass (of dozens or hundreds $\mathrm{GeV}$ ), because the energy of nuclear recoils in these detectors from low mass WIMP are low. To account for yearly modulation effect in DAMA-LIBRA experiment [1] J.Va'vra [2] have supposed that this effect is explained by low mass WIMP scattering on protons in $\mathrm{H}_{2} \mathrm{O}$ molecules which contamination about 1 ppm in NaI crystals.

\section{Spherical Proportional Detector}

The spherical proportional detector was developed for search the low mass WIMP [3].

This detector was filled with $\mathrm{H}_{2}$ or $\mathrm{Ne}$ and has the energy threshold about $100 \mathrm{eV}$.

\section{Double-phase Argon Chamber}

The double-phase argon chamber with mass up to $10^{4}$ tons was proposed for WIMP detection in our work [4]. For electron background suppression was proposed the photosensitive addition $\mathrm{Ge}\left(\mathrm{CH}_{3}\right)_{4}$.

For detecting events in gas-phase was developed the system GEM+ pin -anode with $10 \% \mathrm{H}_{2}$ addition and $\mathrm{K}_{\mathrm{ampl}}=5 \cdot 10^{7}$ [5]. The concentration $\mathrm{H}_{2}$ in liquid $\mathrm{Ar}$ is equal about $100 \mathrm{ppm}$, this allows to detect the low mass WIMP $(\leq 0.5 \mathrm{GeV})$ also because the concentration $\mathrm{H}_{2}$ is 100 time more then in [1].

\section{The Chamber with $\mathrm{Ne}+10 \% \mathrm{H}_{2}(0-1 b a r)$ Filling}

On Fig. 1 is shown the system GEM+ pin-anode, which is used for events detecting in this chamber and in double-phase argon chamber. The fronts of signal in this system is equal $\leq 3 \mu \mathrm{sec}$. The detecting of front allows to measure the event dimension in $\mathrm{z}$-direction for electron background suppression.

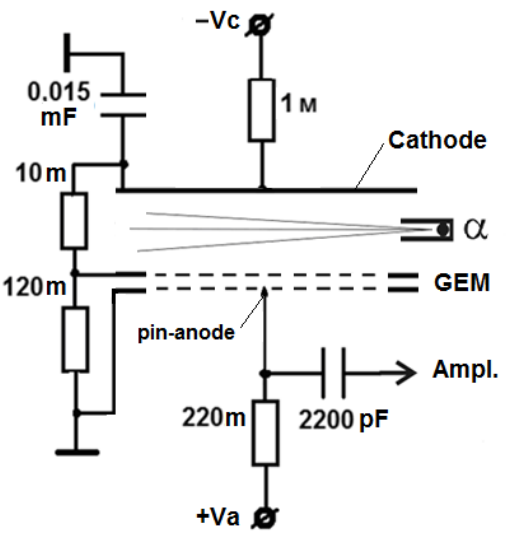

Figure 1. GEM+pin-anode

The addition in chamber of $\mathrm{Ge}\left(\mathrm{CH}_{3}\right)_{4}$ allows to suppress the electron background (gamma-background, $\mathrm{Ar}^{39}$ and tritium decays).

On Fig. 2 the dependence of $\mathrm{K}_{\mathrm{ampl}}$. on potential difference between the pin-anode and GEM is shown. The use in chamber of spectrometric amplifier allows to obtain the energy threshold about $\mathrm{eV}$. This energy threshold allows to search The WIMP with mass $\leq 0.5 \mathrm{GeV} / \mathrm{c}^{2}$ [3]. Double-phase Ar chamber or the chamber with $\mathrm{Ne}+10 \% \mathrm{H}_{2}$ filling are placed in low background laboratory in low background shielding for search the yearly or daily modulation effects. 


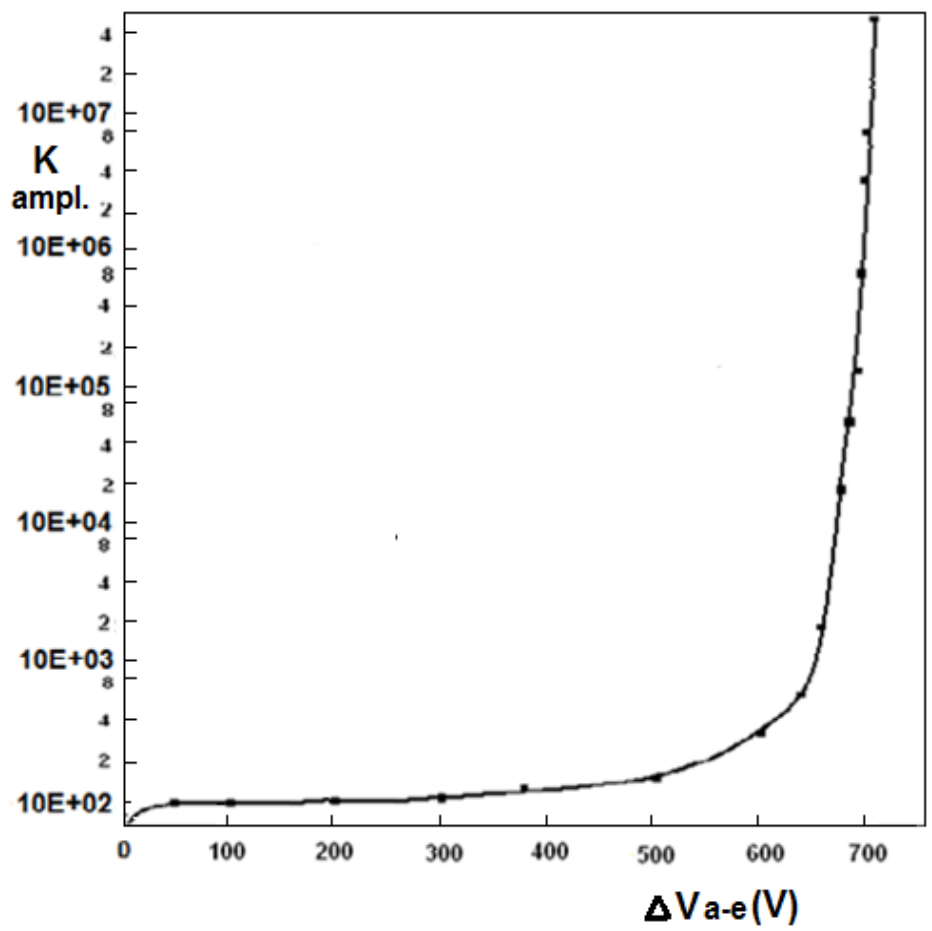

Figure 2. The dependence of $K_{\text {ampll. }}$ on potential difference between the pin-anode and GEM

The chamber with $\mathrm{Ne}+10 \% \mathrm{H}_{2}$ filling is shown on Fig.3.

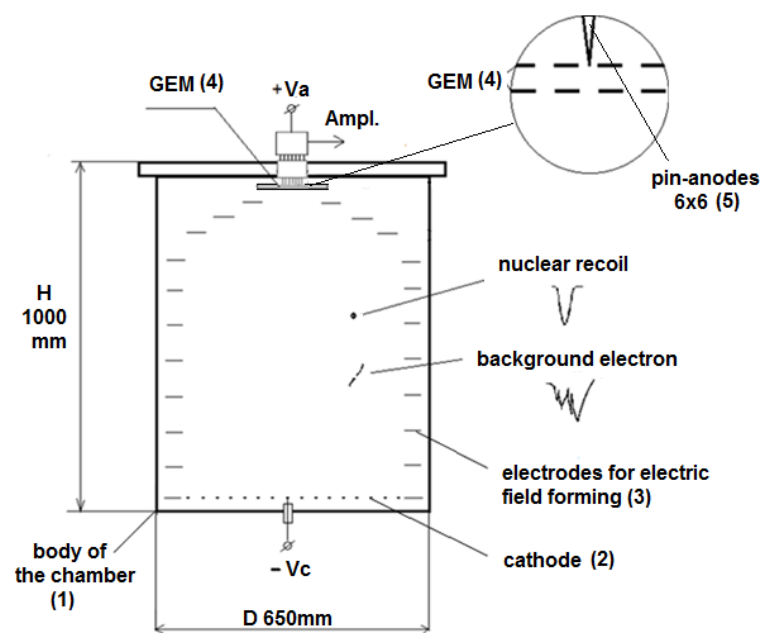

Figure 3. The chamber with $\mathrm{Ne}+10 \% \mathrm{H}_{2}$ filling.

\section{Conclusions}

The method of $\mathrm{H}_{2}$ addition in liquid $\mathrm{Ar}$ and method of event detecting, proposed in this paper allow to search the low mass WIMP in all experiments with Ar chamber.

\section{REFERENCES}

[1] R.Bernabei, P.Belli, F.Cappella, V.Caracciolo, S.Castellano, R.Cerulli, C.J.Dai and A.d'Angelo," Final model independent result of DAMA/LIBRA-phase1", Eur.Phys.J. C73 (2013) 12, 2648R.

[2] J. Va'vra,"A New Possible Way to Explain the DAMA Results" arXiv:1401.0698v5, (2014), Physics Letters B 735 (2014)181.

[3] Y. Giomataris, I. Irastorza, I. Savvidis et al., "A Novel Large-volume Spherical Detector with Proportional Amplification read-out", JINST 3:P09007, (2008).

[4] B.M. Ovchinnikov, Yu .B .Ovchinnikov, V.V. Parusov, "Massive liquid $\mathrm{Ar}$ and $\mathrm{Xe}$ detectors for direct DM searches", JETP Lett. , 96, (2012) 149-152, Universal Journal of Physics and Application 1(2): 66-70,2013.

[5] B.M. Ovchinnikov,V.V. Parusov, "Metods for Detecting Events in Double-Phase Argon Chambers", Instruments and Experimental Techniques, 2013 , Vol.56, No.5 , pp. 516-520. 